\title{
XLII. The propagation of electric waxes along spiral wires, and on an appliance for measuring the length of waves used in wireless telegraphy
}

\author{
J.A. Fleming M.A. D.Sc. F.R.S.
}

To cite this article: J.A. Fleming M.A. D.Sc. F.R.S. (1904) XLII. The propagation of electric waxes along spiral wires, and on an appliance for measuring the length of waves used in wireless telegraphy, Philosophical Magazine Series 6, 8:46, 417-437, DOI: $10.1080 / 14786440409463212$

To link to this article: http://dx.doi.org/10.1080/14786440409463212

曲 Published online: 15 Apr 2009.

Submit your article to this journal

Џll Article views: 4

Q View related articles $\llbracket$

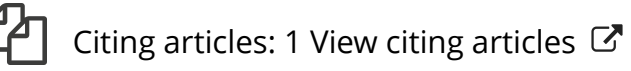


LONDON, EDINBURGH, AND DUBLIN

\title{
PHILOSOPHICAL MAGAZINE
}

\author{
AND \\ JOURNAL OF SCIENCE. \\ [SIXTH SERIES.] \\ $O C T O B E R \quad 1904$.
}

XLII. The Propagation of Electric Waves along Spiral Wires, and on an Appliance for Measuring the Length of Waves used in Wireless Telegraphy. By J. A. Fleming, M.A., D.Sc., F.R.S., Professor of Electrical Engineering in University College, London*.

\section{[Plate XIIL.]}

TTHE propagation of electric waves along wires having helical form has engaged the attention of several physicists, but there are points of interest in connexion with it not entirely exhausted. Hertz has described an experiment in which he established stationary electric waves on a spiral wire, and compared the distance of the nodes with the corresponding distances when the wire was stretched out straight $\uparrow$. He found the internodal distances for the same frequency much smaller in the former case, and he suggests that Maxwell's theory is unable to account for this diminished velocity along the spiral conductor, as compared with that along a straight one.

G. Seibt devised apparatus for showing experimentally the production of stationary electric waves on helices of insulated wire, but his theory of the apparatus was not tested by quantitative experiments or measurements $\ddagger$.

* Communicated by the Author, having been read at the meeting of the British Association at Cambridge, 1904.

+ See "Electric Waves," H. Hertz. English Translation by D. L. Jones, pp. 158, 159 .

† "Elektrische Drahtwellen," G. Seibt, Elektrotechnische Zeitschrift, vol. xxii. April 10, 17, 24, May 1, 8, 1902.

Phil. Mag. S. 6. Vol. 8. No. 46. Oct. 1904. $2 \mathrm{G}$ 
H. C. Pocklington has treated the matter theoretically, and shows that the velocity of the wave along the axis of the spiral should be under some conditions less than that along a straight wire *.

As the production of stationary waves on spiral wires has found practical application in connexion with Hertzian Wave Wireless Telegraphy, particularly in apparatus for syntonization, it seemed desirable to investigate a little more closely the actual facts as a basis for further analysis. The following form of apparatns was therefore arranged, which is very suitable for the metrical study of stationary electric waves.

On a long circular-sectioned wooden rod was uniformly wound a close helix of silk-covered copper wire. The bare wire was No. 32 s.w.G. in size, and the covered wire was $0.4 \mathrm{~mm}$. in diameter. It was laid on in one single layer of 5000 turns. The length of the helix was $200 \mathrm{cms}$., and had therefore 25 turns of wire per centimetre. The outside diameter of the helix was $4.1 \mathrm{cms}$., and the diameter of the circular axis of each single turn was $4.096 \mathrm{cms}$.

The electrical resistance of the wire at $15^{\circ} \mathrm{C}$. was $153 \cdot 2$ ohms. This helix was supported horizontally in a wooden frame at a height of 45 centimetres above the table, and parallel with it was stretched a bare platinoid wire $0 \cdot 2 \mathrm{~mm}$. in diameter, which could be connected to the earth or removed. The distance between the helix and this bare wire was ascertained by a scale placed at each end of the spiral. As this bare wire was connected to the earth, it will be called the " earth-wire."

One end of the helical wire was attached to an electric circuit consisting of a condenser or a pair of leyden-jars, a thick bare copper wire wound in a spiral on a boxwood cylinder, having a sliding contact, thus forming a variable inductance ; and also a spark-gap included in a closed iron box. The spark-balls were connected to an induction-coil capable of giving a 10-inch spark. The electrical arrangements were as shown in fig. 1 (Pl. XIII.). The connecting wires joining the condenser, spark-gap, and variable inductance were formed of thick, insulated, stranded 19/16 copper cables. Parallel to the long helix, and at a distance of $15 \mathrm{cms}$. above it, was arranged a boxwood scale divided into centimetres.

When the induction-coil was set in action, electrical oscillations were generated in the leyden-jar circuit, and by a suitable adjustment of the variable inductance in

* "Electric Oscillations in Wures," H. C. Pocklington, Proc. Camb. Phil. Soc. vol. ix. p. 324, Oct. 25, 1897. 
connexion with the condenser, stationary electric waves were established on the long helical conductor. The position of the nodes and loops of electric force can be most easily ascertained by the employment of a vacuum-tube filled with rarefied Neon. The form of the tube found most useful was similar to that used in spectrum analysis, viz., a couple of bulbs connected by a straight narrow tube, but without platinum electrodes. Such a tube, when held near the helix when the coil was in action, glows brightly with an orange light. If the tabe is held with its axis perpendicular to the axis of the helix at a little distance from it, and then moved along parallel to it, it glows most brilliantly when opposite to the antinodes, but more faintly or not at all when opposite to the nodes. It was found that by exploring the field round the helix in this manner, the position of the nodes could be fixed within a few millimetres*

These experiments are preferably conducted in a partly darkened room. They can, however, be shown to a large audience in broad daylight provided suitable Neon vacuumtubes are used. It is essential to enclose the active sparkgap in the condenser circuit in a metal box, not only to reduce the noise and obseure the light of the spark but also to prevent, as far as possible, the radiation of stray waves directly from the spark-balls. The induction-coil should not be too near, and should be sereened by an interposed metal sheet.

The experiments here described were commenced by a series of careful measurements of the inductances and capacities of the various portions of the apparatus. The author has perfected of late years methods for measuring very small electrical capacities and inductances $\dagger$.

These methods permit a capacity as small as 30 or 40 electrostatic units to be measured with very fair aceuracy, and also an inductance of a few microhenrys.

The condenser first employed in these experiments consisted of two leyden-jars of which the capacity had been measured first separately, then both in parallel, and lastly, both in series; these eapacities being taken at a frequency of 100 .

* Sir William Ramsay was so kind as to lend me a series of vacunmtubes filled with argon, helium, neon, and other rare gases. Of these the neon tube gave the best results, and I am indebted to bim for filling a couple of tubes for me with neon. These tubes glow with a bright orange light in the high-frequency electric field and define the nodes well.

+ See J. A. Fleming and W. C. Clinton, "On the Measurement of Small Capacities and Inductances," Phil. Mag. 1903, vol. v., Gth series, p. 493. Aloo J. A. Fleming, "A Note on the Measurement of Snul]" Uapacities and Inductances," Phil. Mag. May 1904.

$$
2 \mathrm{G} 2
$$


The means of the closely concordant results, obtained by three independent observers, were as follows:-

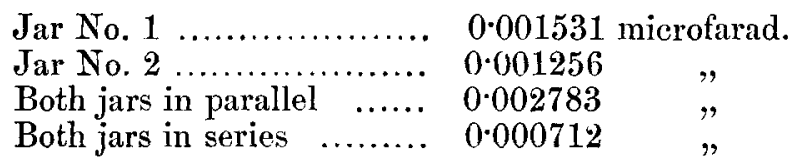

The variable inductance-coil was calibrated in microhenrys* . The inductance of the thick connecting wires joining up the jars, variableinductance, and spark-gap was also measured, and as first used was found to be 2600 centimetres. Subsequently, however, these connexions were shortened so as to make the inductance of the connexion almost negligible.

The next step was to measure the inductance and capacity of the long helix in the position in which it was to be used with the earth-wire at various distances. The inductance was measured by the modified form of Anderson's Bridge method, employing a telephone as a detector as described by the author. (See loc. cit., Phil. Mag. May 1904.)

The following nine values were obtained for the inductance of this helix on different occasions :-

\section{TABLe I.}

Inductance measurements of long Helix of 5000 turns, 200 centims. in length and 4.096 centims. in mean diameter.

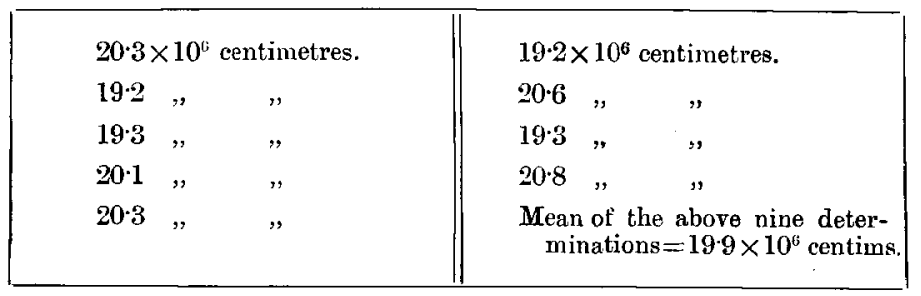

The capacity of the Helix with respect to the earth was then taken by means of the Fleming and Clinton Commutator $t$.

The earth-wire was arranged parallel to the helix and at

* For a description of this inductance-coil see J. A Fleming, "A Note on the Measurement of Small Inductances and Capacities"; and "On a Standard of Small Inductance," Phil. Mag. May 1904. It consisted of a coil of No. 14 S.W.G. copper wire wound in a groove in a boxwood cylinder. The diameter of this cylinder was $10 \mathrm{cms}$., its length $45 \mathrm{cms}$., and it had $2 \cdot 4$ turns of wire per centimetre of length. The total inductance of the coil was $227,000 \mathrm{cms}$.

$\dagger$ For a description of this instrument and mode of using it see Phil. Mag. May 1903. J. A. Fleming \& W. C. Clinton, "On the Measurement. of Small Capacities and Inductances." 
distances from the lower surface of $1,2,3, \&$ c. centimetres successively, and the capacity between the helix and the earth-wire measured in micro-microfarads. (1 micro-microfarad $=10^{-6}$ of a microfarad.)

In Table II. are given the results of the measurements.

\section{TABLE II.}

Capacity of the long Helix of 5000 turns, 200 centims. in length, with respect to the earth-wire placed parallel to it, and at different distances from it.

\begin{tabular}{|c|c|}
\hline $\begin{array}{l}\text { Distance of earth-wire } \\
\text { below the helix. }\end{array}$ & $\begin{array}{l}\text { Capacity of helix with } \\
\text { respect to the earth-wire } \\
\text { or the earth. }\end{array}$ \\
\hline 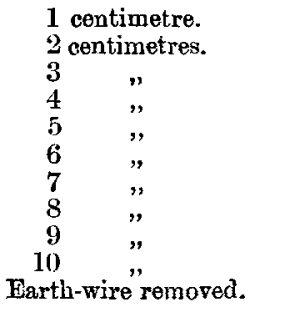 & $\begin{array}{ll}62 \text { micro-microfarads. } \\
51 \cdot 2 & " \\
48 & " \\
45 \cdot 8 & " \\
44 \cdot 4 & " \\
43 \cdot 2 & " \\
42 \cdot 2 & " \\
41 \cdot 2 & " \\
40 \cdot 4 & " \\
39 \cdot 8 & " \\
36 & "\end{array}$ \\
\hline
\end{tabular}

The above values are not the actual figures of observation, but are taken from a curve (see fig. 2, Pl. XIII.) drawn through the plotted observed values to do justice to them all.

It was considered important to ascertain how far the closely wound helix had a capacity with respect to the earth different from that of a hollow metal cylinder of the same length and external diameter. Accordingly the helix was closely covered over with tinfoil and the observations repeated, taking the capacity of this tinfoil cylinder with respect to the earth-wire. These last observations are set out in the upper curve in fig. 2 (Pl. XIII.), and they show that at all distances of the earth-wire there is a nearly constant difference ; the circumscribing tinfoil cylinder being about 6 per cent. greater than the helix in capacity.

Since the tinfoil cylinder was of slightly larger diameter than the coil of wire, this shows that the error made in considering the helix as equivalent to a continuous metal cylinder in regard to electrical capacity is not large. Finally, the helix of wire was set upright and its capacity taken with respect to the earth with no earth-wire near it. This was found to be 35 micro-microfarads, or 0.000036 microfarad. 
We have then to consider how the velocity of an electric wave along such a long helix can be determined. The point of view here adopted is to consider the closely wound helix as if it were a linear cylindrical conductor having a certain mean capacity and inductance per unit of length; these values being obtained from the quotient of the measured values of the total capacity and inductance, by the known length of the spiral. We then proceed to treat the problem as one of electric-wave propagation along a linear conductor in the usual manner.

Let $\mathrm{C}$ be the capacity, $\mathrm{L}$ the inductance, $\mathrm{R}$ the resistance, and $\mathrm{K}$ the dielectric conductance, all per unit of length of an infinitely long helix considered as a simple linear conductor immersed in a dielectric. Then, considering any element $\delta x$ of the length of the helix, if we call $v$ the potential and $i$ the current at the beginning of this element, at any instant we have the well-known equations:

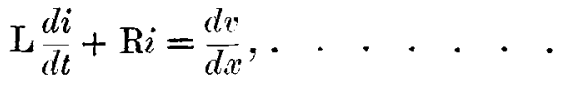

$$
\begin{aligned}
& \mathrm{C} \frac{d v}{d t}+\mathbf{K} v=\frac{d i}{d x}, \quad . \quad . \quad . \quad . \quad . \quad .
\end{aligned}
$$

expressing the current $i$ and potential $v$ at any point in terms of the constants. If we consider $i$ and $v$ to vary in a simple harmonic manner with frequency $n=2 \pi / p$ and to have maximum values $I$ and $V$ (an assumption legitimate in the case of electrical oscillations), then the above equations can be written

$$
\begin{aligned}
& \frac{d \mathrm{~V}}{d x}=(\mathrm{R}+j p \mathrm{~L}) \mathrm{I}, \quad . \quad . \quad . \quad . \quad . \quad . \\
& \frac{d \mathbf{I}}{d x}=(\mathrm{K}+j p \mathbf{C}) \mathrm{V} ; \quad . \quad . \quad . \quad . \quad . .
\end{aligned}
$$

where $j=\sqrt{-1}$. Hence writing $\mathrm{P}$ for

$$
\sqrt{\mathrm{K}+j p \mathrm{~L}} \cdot \sqrt{\mathrm{K}+j p \mathrm{C}}
$$

we can put (3) and (4) in the form

$$
\begin{aligned}
& \frac{d^{2} \mathrm{~V}}{d x^{2}}=\mathrm{P}^{2} \mathrm{~V}, \text {. . . . . . . } \\
& \frac{d^{2} \mathrm{I}}{d x^{2}}=\mathrm{P}^{2} \mathrm{I} \text {. . . . . . . . }
\end{aligned}
$$

A solution of (5) applicable in the present case is

where $a$ and $b$ are constants.

$$
\mathrm{V}=a \epsilon^{+\mathrm{P} x}+b \epsilon^{-\mathrm{P} x}, \quad \text {. . . . . }
$$


If we apply this to the case of a semi-infinite cable having a simple harmonic electromotive force of maximum value $\mathbf{E}$ acting at one end and reckon $x$ in the direction in which $\mathrm{V}$ decreases, then, since in this instance $\mathrm{V}=0$ when $x=\infty$, we must have $b=0$, and therefore

$$
\mathrm{V}=\mathrm{E} e^{-\mathrm{P} x} ;
$$

or, since $\mathrm{P}$ can be written in the form $\alpha+j \beta$, we have the following vector equation for the potential at $x$ :

$$
\mathrm{V}=\mathrm{E}^{-\alpha x}(\cos \beta x-j \sin \beta x) . \quad . \quad .
$$

Hence, it follows that the wave-length of the potential distribution along the conductor is $2 \pi / \beta$ and the wave velocity is $p / \beta^{*}$.

In the above equations $x$ is to be understood as a distance measured along the axis of the helix, not along the spiral path of the wire.

If we may consider, as we may in this case, since $p$ is very large, that $\mathrm{R}$ and $\mathrm{K}$ are negligible in comparison with $p \dot{\mathrm{L}}$ and $p \mathrm{C}$, then $\mathrm{P}^{2}$ reduces to $-p^{2} \mathrm{CL}$; and it follows at once from (9) that the wave-length $\lambda$ of the motion expressed by these equations under these conditions is given by

$$
\lambda=1 / n \sqrt{\mathrm{CL}} \text {. }
$$

Hence the wave velocity $W=1 / \sqrt{\mathrm{CL}}$.

We can therefore calculate the wave velocity along the spiral if we know by experiment the capacity per unit of length (C) and the inductance per unit of length (L) of the helix.

The length of the helix is 200 centimetres and its total inductance $19.9 \times 10^{6} \mathrm{cms}$, and its total capacity is $\mathrm{C}_{0}$ micromicrofarads (m.mfds.) depending on the distance of the parallel earth-wire. Hence, the wave velocity along the helix is given by the equation

$$
\mathrm{W}=\frac{200 \times \sqrt{10^{21}}}{\sqrt{\text { Capacity in m.mfds. } \times \text { Inductance in cms. }}} .
$$

* If we multiply this equation (9) by $\epsilon^{j p t}$ and take the real part of the resulting expression, we have $v=\mathrm{Ee}^{-\alpha x} \cos (p t-\beta x)$, which gives us the ordinary algebraic expression for the potential at any point and time in the cable. See J. A. Fleming, "On a Model illustrating the Propagation of a Periodic Current in a Telephone Cable, and the Simple Theory of its Operation," Phil. Mag. August 1904. 
The conversion of micro-microfarads to electromagnetic units of capacity involves the factor $10^{21}$.

Hence the above may be written

$$
\mathrm{W}=\frac{20000 \times 10^{6}}{\sqrt{1 \overline{99 \mathrm{C}_{0}}}} \ldots . . \quad . \quad . \quad .
$$

Below is a Table showing the calculated values of the wave velocity $W$ along the spiral for various observed values of the total capacity $\mathrm{C}_{0}$ (in m.mfds.) for different distances of the earth-wire.

\section{TABLE III.}

Electric-wave velocity along a long Helix of 5000 turns, $4.1 \mathrm{cms}$. diameter, and $200 \mathrm{cms}$. in length, calculated from the measured inductance and capacity of the helix.

\begin{tabular}{|c|c|c|}
\hline $\begin{array}{c}\text { Distance of earth- } \\
\text { wire below helix. } \\
d .\end{array}$ & $\begin{array}{l}\text { Capacity of helix in } \\
\text { micro-microfarads. } \\
\mathbf{O}_{0} .\end{array}$ & $\begin{array}{c}\text { Ware-relocity along } \\
\text { helix in centims. } \\
\text { per see. } \\
W .\end{array}$ \\
\hline 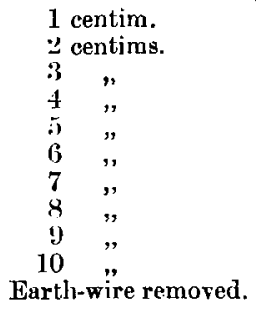 & $\begin{array}{l}6 \cdot 2 \cdot 0 \mathrm{~m} . \mathrm{mfds} . \\
51 \cdot 2 \quad, \\
48 \cdot 0 \quad ", \\
45 \cdot 8 \quad ", \\
44 \cdot 4 \quad, \\
43 \cdot 2 \quad ", \\
42 \cdot 2 \quad ", \\
41 \cdot 2 \quad ", \\
40 \cdot 4 \quad " \\
39 \cdot 8 \quad, \\
36 \cdot 0 \quad ",\end{array}$ & 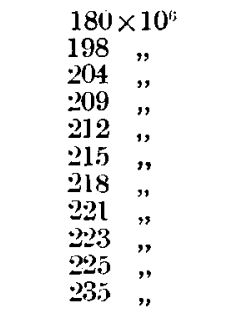 \\
\hline
\end{tabular}

Hence the wave-velocity along the helix when isolated in space approximates to $235 \times 10^{6}$ centimetres per second or $1 \frac{1}{2} 5$ part of the velocity of æther waves in free space or along a straight wire.

Since the division of the total inductance and capacity by the length of the helix gives us only the mean inductance and capacity per unit of length, the above values of the wavevelocity are also mean values.

The author has shown that the inductance per unit of length of a spiral is numerically equal to the square of the length of the wire wound on per unit length of the helix, and also that the capacity of a helix per unit of length 
diminishes as the turns per centimetre diminish. Hence, if we suppose such a helix gradually pulled out into a straight wire whilst being traversed by electric waves of constant frequency, the wave-velocity would gradualy increase up to the velocity of radiation, viz., to $3 \times 10^{10} \mathrm{cms}$. $/ \mathrm{sec}$., which value it would reach when the helix was stretched out into a straight wire. In the case, however, of a closely-wound helix, the velocity of electric waves along it in the direction of the axis is much less than the velocity of free waves in space.

The simple analysis above given is inadequate to deal with the more difficult problem of a very open spiral. If a closewound spiral were gradually stretched out, the velocity of the wave along it would increase, and at some pitch would reach that of radiation. The precise pitch of the spiral at which this would happen is of mathematical interest, but no doubt difficult to predetermine.

The next step was to measure the wave-lengths for various frequencies.

The inductance in the jar circuit was first adjusted to produce the fundamental oscillation of the long helix and establish a stationary wave on the spiral with a loop or antinode of potential at the free end ; and then subsequently adjusted to produce the series of odd harmonies with wavelengths in the ratio of $1 / 3 \mathrm{rd}, 1 / 5 \mathrm{th}, 1 / 7 \mathrm{th}, 1 / 9 \mathrm{th}, 1 / 11$ th of that of the fundamental. The position of the nodes was then carefully ascertained by the aid of the Neon vacuum-tube, and found to be as shown in the diagram on fig. 3 (Pl. XIII.), where $O$ is the open end of the helix and $E$ the end at which the electromotive force is applied, and the numbers represent the distances in centimetres separating the nodes $N_{1}, N_{2}$, \&c. from each other and from the free ends of the helix.

These observations have been very carefully repeated on many occasions, aud the figures given are the means of the best results.

Coincidently with the measurements of the internodal distances the inductance inserted in the leyden-jar circuit was noted, and also the distance of the earth-wire below the helix.

Observations were made with the earth-wire at various distances in the case of the fundamental and 1st harmonic oscillations; and the results are given in Tables IV., V., and VI. The frequency $n$ of the oscillations in the jar circuit is calculated from the values of the inductance and the capacity 
in that circuit by the formula *

$$
n=\frac{5 \times 10^{6}}{\sqrt{\text { Capacity in microfarads } \times \text { Inductance in centims. }} .}
$$

Table IV.-Measured Inductances and Calculated Frequencies in the Leyden-jar Circuit corresponding to the Fundamental Electrical Oscillation of the Spiral and to different distances of the Earth-wire.

Capacity of the leyden-jars $=0.0028$ microfarad.

\begin{tabular}{|c|c|c|}
\hline $\begin{array}{l}\text { Distance of earth- } \\
\text { wire from helix } \\
\text { in centims. }\end{array}$ & $\begin{array}{c}\text { Inductance of jar } \\
\text { circuit in } \\
\text { centims. } \\
\text { L. }\end{array}$ & $\begin{array}{c}\text { Calculated freipency } \\
\text { of the oseillation. } \\
n .\end{array}$ \\
\hline $\begin{array}{c}2 \\
3 \\
4 \\
5 \\
6 \\
7 \\
8 \\
8.5 \\
\text { Earth-wire removed. }\end{array}$ & $\begin{array}{l}193,600 \\
157,600 \\
150,600 \\
141,600 \\
132,600 \\
123,600 \\
111,600 \\
107,600 \\
102,600\end{array}$ & $\begin{array}{l}0.215 \times 10^{\prime} \\
0.238 \quad " \\
0.243 \quad " \\
0.251 \quad " \\
0.260 \quad " \\
0.269 \quad " \\
0.283 \quad " \\
0.288 \quad " \\
0.295 \quad "\end{array}$ \\
\hline
\end{tabular}

TABLE V.-Measured Inductances and Calculated Frequencies in the Leyden-jar Circuit corresponding to the First Harmonic Electrical Oscillation of the Spiral and to different distances of the Earth-wire.

Capacity of leyden-jars $=0.00071$.

\begin{tabular}{|c|c|c|}
\hline $\begin{array}{l}\text { Distance of earth- } \\
\text { wire from helix } \\
\text { in centims. }\end{array}$ & $\begin{array}{l}\text { Inductance of jar } \\
\text { circuit in centims. } \\
\text { L. }\end{array}$ & $\begin{array}{c}\text { Calculated frequency } \\
\text { of the oscillation. } \\
n\end{array}$ \\
\hline $\begin{array}{c}2 \\
3 \\
4 \\
5 \\
6 \\
7 \\
8 \\
8 \cdot 5 \\
\text { Earth-wire remored. }\end{array}$ & $\begin{array}{l}76,100 \\
68,600 \\
67,100 \\
62,600 \\
59,600 \\
56,600 \\
54,600 \\
52,600 \\
50,600\end{array}$ & $\begin{array}{l}0.680 \times 10^{6} \\
0.717 \quad ", \\
0.725 \quad ", \\
0.750 \quad ", \\
0.769 \quad ", \\
0.789 \quad ", \\
0.802 \quad ", \\
0.818 \quad \text { ", } \\
0.834 \quad \text { ", }\end{array}$ \\
\hline
\end{tabular}

* See J. A. Fleming, Cantor Lectures before the Society of Arts of London. "On Electrical Oscillations of Electric Wares," 1901. Lecture I. 
The inductances required in the jar circuit to produce the first, second, fourth, and tifth harmonics were also determined for lcertain distances of the earth-wire and also when the earth wire was removed, the position of the nodes being at the same time taken. The first node is that nearest to the open end of the spiral farthest removed from the end at which the electromotive force is applied. All theories of the production of stationary waves on wires agree in making the distance between the first and second nodes equal to one half of a wave-length. Hence these distances are given in Table VI., and for comparison the frequency of the fundamental for the same earth-wire distance.

TABLE VI.-Measured values of the Inductances and Capacities in the Condenser Circuit and Calculated Frequencies required to produce the Fundamental and the various Harmonics on the Helix.

Glass Condenser.

\begin{tabular}{|c|c|c|c|c|c|}
\hline Oscillation. & $\begin{array}{c}\text { Inductance } \\
\text { in centims. } \\
\text { L. }\end{array}$ & $\begin{array}{c}\text { Capacity } \\
\text { in mfds. } \\
\text { C. }\end{array}$ & $\begin{array}{c}\text { Frequency. } \\
n .\end{array}$ & $\begin{array}{c}\text { Wave- } \\
\text { length. } \\
\lambda .\end{array}$ & $\begin{array}{c}\text { Velocity } \\
n \lambda .\end{array}$ \\
\hline \multicolumn{6}{|c|}{ Earth-wire 2 cms. down. } \\
\hline 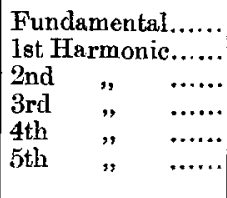 & $\begin{array}{r}193,600 \\
69,100 \\
26,600 \\
15,100 \\
10,600 \\
8,600\end{array}$ & $\begin{array}{l}0.0028 \\
0.00071 \\
\quad, \\
" \\
\Rightarrow \\
"\end{array}$ & $\left|\begin{array}{cc}.215 & \times 10^{\circ} \\
.714 & " \\
1 \cdot 151 & " \\
1.533 & " \\
1.823 & " \\
2 \cdot 023 & "\end{array}\right|$ & $\begin{array}{r}920 \\
276 \\
160 \\
115 \\
88 \\
72\end{array}$ & $\begin{array}{l}198 \times 10^{\circ} \\
197 ", \\
184 ", \\
176 ", \\
160 " \\
146 "\end{array}$ \\
\hline \multicolumn{6}{|c|}{ Earth-wire 3 cms. down. } \\
\hline 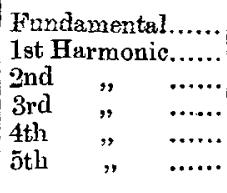 & $\begin{array}{r}157,600 \\
68,600 \\
26,600 \\
15,100 \\
10,600 \\
8,600\end{array}$ & $\begin{array}{l}0.0028 \\
0.00071 \\
\quad, \\
\Rightarrow \\
\Rightarrow \\
",\end{array}$ & $\begin{array}{rl} & .238 \times 10^{6} \\
.717 & " \\
1.151 & " \\
1.533 & " \\
1.823 & " \\
2.023 & "\end{array}$ & $\begin{array}{r}857 \\
280 \\
160 \\
115 \\
88 \\
72\end{array}$ & $\begin{array}{l}204 \times 10^{\circ} \\
201 " \\
184 " \\
176 ", \\
160 " \\
146 "\end{array}$ \\
\hline \multicolumn{6}{|c|}{ Earth-wire removed. } \\
\hline 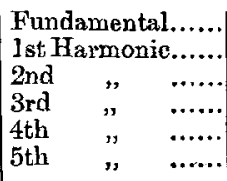 & $\begin{array}{r}102,600 \\
50,600 \\
21,600 \\
13,600 \\
10,100 \\
7,100\end{array}$ & $\begin{array}{c}0.0028 \\
0.00071 \\
, \\
", \\
", \\
"\end{array}$ & $\left|\begin{array}{cc}.295 \times 10^{6} \\
.834 \\
1.306 & " \\
1.610 & " \\
1.87 & " \\
2.23 & "\end{array}\right|$ & $\begin{array}{r}800 \\
280 \\
160 \\
115 \\
88 \\
72\end{array}$ & $\begin{array}{l}236 \times 10^{6} \\
233 " \\
209 " \\
185 " \\
164 " \\
171 "\end{array}$ \\
\hline
\end{tabular}


Concerning the figures in Table VI., the following remarks may be made :-

In the first place, the wave-lengths for the five barmonic oscillations, which are equal to double the measured distance between the first and second nodes, are very nearly in the ratio of the numbers $3,5,7,9$, and 11 , and the mean of the products $3 \times 280,5 \times 160,7 \times 116,9 \times 88$, and $11 \times 72$ is 807 , or very nearly four times the length of the helix.

On the other hand, the calculated frequencies $(n)$ for the higher harmonics do not follow those of the fundamental and first harmonic in the ratio of the numbers $1,3,5,7,9,11$; and there is therefore a continual falling off in the product $(n \lambda)$ of the frequency in the condenser circuit and the wavelength on the spiral. In the case of the fundamental and first harmonic when the earth-wire was removed, this product agrees with the velocity of the wave along the spiral as ealculated from the capacity and inductance per unit of length of the belix. The first suggestion which occurred on considering this discrepancy was that the dielectric constant, and therefore the capacity of the glass condenser, might perhaps decrease as the frequency increased. It has been shown by Prof. J. J. Thomson and by M. R. Blondlot, that at a frequency of $25 \times 10^{6}$ the dielectric constant of glass falls to a value of 2.7 or $2.8^{*}$, and it seemed possible that this decadence might set in at a frequency as low as $10^{6}$. It has, however, been found that sulphur and ebonite do not exhibit this decrease of dielectric constant under increased frequency of electric force. Accordingly two other condensers were constructed of sheets of good ebonite, $3 \mathrm{~mm}$. in thickness. These sheets were partly covered on both sides with rectangles of tinfoil, each having an area of $15 \times 17.5$ centimetres, and two condensers were made up, each consisting of five of such coated plates. These were immersed in vaseline oil contained in an ebonite box.

The capacity of these ebonite condensers was measured and found to be as follows:-The two ebonite condensers in parallel had a capacity of 0.0025 microfarad, and in series had a capacity of 0.00062 microfitrad.

Another source of error was at the same time discovered and correction made for it. It was found that the inductance of the spiral wire wound on a boxwood cylinder which was used as a variable inductance in the condenser circuit had a

* See Prof. J. J. Thomson, Proc. Roy. Soc. vol. xivi. p. 298 (1889), "On Specific Inductive Capacities of Dielectrics under vapidly alternating Electric Forces"; also M. R. Blondlot, Comptes Rendus, vol. cxii. p. 1058 (1891). 
less effective inductance when used with the high frequency oscillations than when measured with alternating currents of low frequency. This was discovered to be due to the proximity of the turns of wire permitting a certain dielectric current to pass from turn to turn, or else a true conductor current to flow through the boxwood.

Investigation showed that when employing a spiral wire as an inductance, measurements of the inductance at low frequency could not be considered as giving the true value of the inductance for high frequency oscillations. Even when the wire was wound as an open spiral with no solid dielectric as a core, there was still an uncertainty as to the true inductance. This led to a long series of experiments on the construction of small inductances of a form for which the inductance could be predelermined by calculation for high frequency oscillations. It was discovered that no form is so convenient as that of a long wire, bent into the form of a square with the ends brought out parallel at one corner and of the shape shown in fig. 4 (see Pl. XIII.).

If $S$ is the length of the side of the square in centimetres, and if $d$ is the diameter of the wire of which it is made, then the inductance $\mathrm{L}$ of the square in centimetres is given by the equation

$$
\mathrm{L}=8 \mathrm{~S}\left\{2 \cdot 303 \log _{10} \frac{16 \mathrm{~S}}{d}-2 \cdot 6\right\} .
$$

If the tails of parallel wire by which the current is brought to the square have a length $l$, and are at a distance $\mathrm{D}$ centimetres apart, then these create an additional inductance $L^{\prime}$, where

$$
L^{\prime}=2 l\left\{4 \cdot 606 \log _{10} \frac{2 \mathrm{D}}{d}+\frac{1}{2}\right\} .
$$

Hence the total inductance is $\mathrm{L}+\mathrm{L}^{\prime}$. Five squares of wire were accordingly constructed of copper wire 2 millimetres in diameter. The sides of these squares in centimetres and feet

\begin{tabular}{|c|c|c|}
\hline Square. & Length of side. & Calculated Inductance. \\
\hline 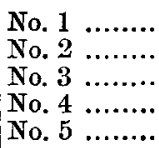 & $\begin{array}{l}823 \cdot 5 \mathrm{cms}=27 \mathrm{ft} . \\
427 \quad "=14 \mathrm{ft} . \\
256 \quad "=8 \mathrm{ft} .3 \text { ins. } \\
168 \quad "=5 \mathrm{ft.} 7 \frac{1}{2} \text { ins. } \\
132 \quad "=4 \mathrm{ft.} .4 \text { ins. }\end{array}$ & $\begin{array}{l}=56,000 \mathrm{cms} . \\
=26,747 \quad " \\
=15,011 \quad " \\
=9,274 \quad " \\
=7,470 \quad "\end{array}$ \\
\hline
\end{tabular}
and inches, and calculated inductances, were as follows :- 
The above squares were found by a process of trial and failure to have inductances which, when used in conjunction with the two ebonite condensers in series having a capacity of $0.00062 \mathrm{mfd}$., tuned with the five harmonic oscillations of the spiral.

By the aic of these observations the scale-readings of the inductance on the boxwood cylinder were corrected to give true values, and these last values have been employed in Tables IV., V., and VI. The whole of the observations were then repeated, using the ebonite condensers and these square wire inductances of predetermined value to form the oscillating circuit. The position of the nodes was carefully determined by the aid of two neon vacuum-tubes, and the results are tabulated in 'Table VII. The eapacity $\mathrm{O}$ is the measured capacity in the condenser circuit. The inductance $\mathrm{L}$ is the calculated value of the square inductance on wire of $2.03 \mathrm{~mm}$. diameter in the form of a square used. The frequency $n$ is calculated from the values of $\mathrm{C}$ and $\mathrm{L}$. The wave-length $\lambda$ is twice the measured distance between the first and second nodes on the helix, and the wave-velocity $W$ is the product $n \lambda$ of the calculated frequency and the observed wave-length. The wave-length of the fundamental $(840 \mathrm{cms}$. is obtained by dividing the velocity obtained from the 1st harmonic by the calculated frequency for the fundamental.

TABLE VII.-Inductances and Capacities and Calculated Frequencies in the Condenser Cireuit required to produce the findamental and Harmonic Oscillations in the long: Helix.

Ebonite condenser and square inductances used.

\begin{tabular}{|c|c|c|c|c|c|}
\hline Oseillation. & $\begin{array}{c}\text { Capacity: } \\
\text { C. }\end{array}$ & $\begin{array}{c}\text { Inductance, } \\
\mathrm{L} .\end{array}$ & $\begin{array}{c}\text { Frequency. } \\
n .\end{array}$ & $\begin{array}{c}\text { Wave- } \\
\text { length. } \\
\lambda .\end{array}$ & $\begin{array}{l}\text { Wave- } \\
\text { velocity. } \\
W=i \lambda .\end{array}$ \\
\hline $\begin{array}{l}\text { Fundamenial..... } \\
\text { lst Harmonic.... }\end{array}$ & $\begin{array}{l}0.0055 \\
000062\end{array}$ & $\begin{array}{l}56,000 \\
56,000\end{array}$ & $\begin{array}{l}028 \times 10^{6} \\
0.847\end{array}$ & $\begin{array}{l}840 \\
280\end{array}$ & $\begin{array}{l}235 \times 10^{6} \\
235\end{array}$ \\
\hline end & (1) & 26,747 & 1.23 & 166 & $204 "$ \\
\hline Brd & $"$ & 15,011 & $1 \cdot 64 \quad$ & 115 & 189 \\
\hline th $\quad, \quad \ldots$. & ," & 9,274 & $2 \cdot 08$ & 88 & 183 \\
\hline 5th $\quad, \quad \ldots$. & $"$ & 7,470 & 232 & 72 & $167 "$ \\
\hline
\end{tabular}

It is seen, therefore, that the velocity obtained from the measurements made with the 1st harmonic, viz., $235 \times 10^{6}$ cms./sec., agrees exactly with that calculated from the inductance and capacity per unit of length of the helix. On 
the other hand, the velocity obtained from the higher harmonics is decidedly less. As there can be very little doubt but that the values given in Table VII. for the inductances and capacities for the condenser circuit corresponding to each harmonic are substantially correct, the only conclusion which can be drawn is that the wave-velocity along the helix is in some way or other diminished as the frequency increases.

After numerous experiments and measurements designed to eliminate other possible causes for this diminution, it was found that ordinary dry wood has decided conductivity for high-frequency currents of the order of $10^{6}$. This can be shown in the following manner. If a stationary oscillation is excited in the spiral and a vacuum-tube placed near to, but not at a node, it glows feebly. If then a thick sheet of ebonite is interposed it does not affect the glow. If, however, a wood board is interposed, the glow ceases. The wood has conductivity enough to act as a screen for highfrequency oscillations; accordingly it appears that the wooden rod on which the silk-covered wire forming the helix is wound must have conductivity sufficient at or above a frequency of $10^{6}$ to act as an earth-wire.

On referring to Table III. it will be seen that as the earthwire was brought nearer to the helix, the velocity of the wave along it decreased because the capacity of the helix was increased.

When the earth-wire was removed, the velocity was $235 \times 10^{6} \mathrm{cms}$./sec. as calculated from the capacity and inductance. When the earth-wire was brought within $1 \mathrm{~cm}$. distance of the helix, the velocity fell to $180 \times 10^{6} \mathrm{cms}$. $/ \mathrm{sec}$. Hence it is not inconsistent to conclude that for frequencies above $10^{6}$ the capacity of the helix is increased by the growing conductivity of the wooden rod within it, and the wavevelocity gradually falls from $235 \times 10^{6}$ down to $180 \times 10^{6}$ or $170 \times 10^{6}$ as the frequency is increased to obtain the various harmonics.

To confirm the above results, experiments were also made with oscillations set up in the helix when the end remote from the condenser circuit was earthed. In this case the harmonics resemble those established in an open organ-pipe, and their frequency increases in accordance with the natural numerals, whereas with the far end of the helix insulated they follow the law of the odd numbers.

A square inductance was made consisting of one turn of No. 14 copper wire bent into a square, of which the side was 6 feet $11 \frac{1}{2}$ inches in length, or 212 centimetres. The perimeter was 846 centimetres and the calculated inductance 12,077 
centimetres. 'This inductance was associated with an ebonite condenser of 0.0015 microfarad capacity, and it was found that when the long helix was connected to this oscillating circuit with the far end earthed, that stationary oscillations were set up in it which had a node at the centre of the belix. This was therefore the first overtone. From the capacity $0.0015 \mathrm{mfd}$. and inductance $12,077 \mathrm{cms}$., we find the frequency in the oscillating circuit was $1 \cdot 174 \times 10^{6}$. Since the wave-length is equal to the whole length of the helix, viz., 200 centimetres, it follows that the wave-velocity should be

$$
200 \times 1 \cdot 174 \times 10^{6}=234.8 \times 10^{6} \mathrm{cms} . / \mathrm{sec} .
$$

This, however, is almost exactly the wave-velocity calculated from the constants of the helix.

Again, the capacity was increased to 0.006 microfarad, and it was then found that the stationary oscillation set up on the helix was the fundamental having an antinode at the centre.

This capacity $0.006 \mathrm{mfd}$. and inductance 12,077 centims. corresponds to a frequency of $0.587 \times 10^{6}$, and the wavelength is 400 centims. Hence, here also the wave-velocity is $400 \times 0 \cdot 587 \times 10^{6}=234.8 \times 10^{6} \mathrm{cms} . / \mathrm{sec}$.

On taking a higher frequency still, it was found that an inductance of $22,000 \mathrm{cms}$. and a capacity of $0.00062 \mathrm{mfd}$. in the condenser circuit excited on the helix a wave of length 150 centimetres. This capacity and inductance correspond to a frequency of $1.37 \times 10^{6}$, and this again to a wave-length of $150 \mathrm{cms}$. Hence the wave-velocity is $205 \times 10^{6} \mathrm{cms} . / \mathrm{sec}$. Accordingly, here again we find that with increased frequency the velocity of the wave along the helix with a wooden core decreases.

To eliminate all doubt as to the effect of the conductivity of the wooden rod, a pair of new helices of wire were constructed, each consisting of a thick ebonite tube wound over with one layer of double silk-covered copper wire.

These helices will be called Helix A and Helix B.

The length of each tube was $215 \mathrm{cms}$., and outside diameter 4.75 cms. The wire was No. 30 s.w.G., and after being wound on in closely adjacent turns was lightly varnished with shellac varnish made up with absolute alcohol. The lengths, diameters, and turns of each helix were as follows:-

Helix A. Number of turns $=5465$. Length of helix $=$ 210 centimetres. Mean diameter of one turn $=4 \cdot 78$ centims.

Helix B. Number of turns $=5476$. Length of helix $=$ 210 centims. Mean diameter of one turn $=4 \cdot 76$ centims. 
From the above values the inductance $L$ of each helix was calculated from the formula

$$
\mathrm{L}=\pi^{2} d^{2}\left(\begin{array}{c}
\mathrm{N} \\
l
\end{array}\right)^{2} l, \text { where } \pi^{2}=9 \cdot 87 .
$$

Hence Inductance of helix $A=32.07 \times 10^{6} \mathrm{cms}$.,

and Inductance of helix $\mathrm{B}=31.93 \times 10^{6} \mathrm{cms}$.

The capacity of each helix with respect to the earth was measured with the helix supported horizontally and at a height of $50 \mathrm{cms}$, above the table.

The values were as follows:-

Capacity of helix $A=0.000045$ microfarad. Capacity of helix $B=0.0000462$ microfarad.

From these figures the velocity of propagation of the wave along each helix was calculated as above described and found to be :-

Velocity along helix $\mathrm{A}=174.8 \times 10^{6} \mathrm{cms}$. $/ \mathrm{sec}$.

Velocity along helix $B=172.9 \times 10^{6} \mathrm{cms} . / \mathrm{sec}$.

Hence it may be taken as 174 million centimetres per second.

The above-described spirals were supported on insulating stands in a horizontal position, and one end was connected to an oscillating circuit consisting of a condenser made of sheet ebonite covered with tinfoil, an inductance-coil, and a spark-gap. The condenser consisted of 24 ebonite plates immersed in vaseline oil, the plates being grouped in six sections of four plates each. The capacity of the sections $s$ me asured, and found to be as follows :-

$$
\begin{aligned}
& \text { Section } 1 \ldots \ldots \ldots \text {...... 0.001030 microfarad. } \\
& \text { Section } 2 \text {......... 0.001005 " } \\
& \text { Section 3 .......... 0.000913 ", } \\
& \text { Section } 4 \text {.......... } 0.000919 \quad " \\
& \text { Section } 5 \text {........... 0.000994 " } \\
& \text { Section } 6 \text {........... 0.000974 , } \\
& \text { Total capacity ..... } 0 \cdot 005835, \\
& \text { Sections } 4+5+6 \ldots 0.002887 \quad, \\
& \text { Sections } 1+2+3 \ldots 0.002948 \text { ", } \\
& \text { Sections } 1+2+3 \text { in series with sections } 4+5+6
\end{aligned}
$$
$=0 \cdot 001461 \mathrm{mfd}$.

The variable inductance used with the condenser had been previously calibrated by comparing certain parts of it with the calculated inductance of squares of wire of known size.

The inductance and capacity were then arranged so as to Phil. Mag. S. 6. Vol. 8. NTo. 46. Oct. 1904. $2 \mathrm{H}$ 
produce the frequency of oscillation required to set up the fundamental or higher harmonic oscillations in one of the helices, and the wave-lengths measured as already described with the Neon vacuum-tube. 'The results of these observations are set out in the following Table VIII.

Table VIII._Observations made with Helix A with Ebonite Core and with Ebonite Condenser, variable Inductance, and Neon Vacuum-tube, to determine the Wave-velocity along the Helix.

\begin{tabular}{|c|c|c|c|c|c|}
\hline Oscillation. & $\begin{array}{l}\text { Capacity } \\
\text { in mfds. in } \\
\text { condenser } \\
\text { circuit. } \\
\text { C. }\end{array}$ & $\begin{array}{c}\text { Induetance } \\
\text { in cms. in } \\
\text { condenser } \\
\text { circuit. } \\
\text { L. }\end{array}$ & $\begin{array}{c}\text { Calculated } \\
\text { frequency } \\
n .\end{array}$ & $\begin{array}{c}\text { Observed } \\
\text { wave- } \\
\text { length. } \\
\lambda .\end{array}$ & $\begin{array}{c}\begin{array}{c}\text { Calculated } \\
\text { ware- } \\
\text { velocity. } \\
\mathrm{W}=n \lambda .\end{array}\end{array}$ \\
\hline Fundamental.... & 0.005835 & 110,000 & $0.197 \times 10^{6}$ & $(871)$ & $\left(172 \times 10^{6}\right)$ \\
\hline 1stHarmonic..... & 0.002887 & 25,000 & 0.588, & 292 & 172 \\
\hline 2nd $\quad$, & 0.001461 & 18,000 & $0 \cdot 977$ & 175 & 172 \\
\hline $3 r d$ & 0.001464 & 9,000 & $1 \cdot 379$, & 124 & 171 \\
\hline 4th & 0.001461 & 6,000 & $1 \cdot 70$ & 95 & 163 \\
\hline 5 th & 0001461 & 5,000 & 1.9 & 80 & 152, \\
\hline
\end{tabular}

From the above observed values it is seen that the wavelengths of the 1st, 2 nd, and 3rd harmonics are very nearly in the ratio of $3: 5: 7$ for $292 \times 3=876,175 \times 5=875$, and $124 \times 7=868$. Hence the fundamental wave-length should be 871 . If we insert the value in Table VIII. and calculate the wave-velocity for the fundamental frequency, we find it to be $172 \times 10^{6} \mathrm{cms}$. per second, or exactly the same value as that obtained for the three succeeding harmonics.

Hence from the fundamental and the three succeeding higher harmonics, we obtain values for the wave-velocity which are closely identical and equal to $172 \times 10^{6} \mathrm{cms}$. $/ \mathrm{sec}$, and in very near agreement with the velocity of $174 \times 10^{6} \mathrm{cms} . / \mathrm{sec}$. calculated from the constants of the helix itself.

There is a slight falling off in the velocity obtained from the 4th and 5th harmonics, but the difficulty of measuring the small inductance then used in the condenser circuit is considerable.

Hence we may say that when a helix wound on an ebonite core is used, observations confirm theory substantially, and show us that the stationary waves are formed as predicted, the wave-velocity being calculable from the observed inductance and capacity of the helix. 
The conclusions which may be drawn from this research are is follows:- -

(i.) In the construction of inductances and helices for such experiments as are here described, they should be wound on ebonite and not on wooden cores.

(ii.) Spirals of wire, if the turns are at all close, have less inductance for frequencies of the order of a million than for frequencies of the order of 100 , on account of the dielectric current passing between the turns.

(iii.) The best form to give to a standard of inductance for high frequency work is a single wire bent into a circle or a square.

(iv.) The velocity of an electric wave along a closely wound helix of wire is measured by the reciprocal of the square root of the product of its capacity and inductance per unit of length.

(v.) The distance from the open end of the helix to the first node is always much less than a quarter of a wavelength, in fact, nearly one-fifth of a wave-length.

(vi.) 'The distance between the first and second nodes rockoned from the free or insulated end of the helix is onehalf of a wave-length.

(vii.) If the fundamental oscillation is set up in a helix by attaching one end to an oscillating circuit tuned to it, the wave-length is rather more than four times the length of the helix, but not five times.

The above described apparatus can be used with some modification for the determination of the wave-lengths of the rether waves employed in Hertzian wave wireless telegraphy.

The frequencies used for the above purpose lie generally between the limits of $0.5 \times 10^{6}$ and $3 \times 10^{6}$.

The following is the arrangement required (see fig. 5, Pl. XIII.). In all the transmitters now used for Hertzian wave-telegraphy there is an oscillating circuit consisting of an inductance, a capacity, and a spark-gap. This is directly or inductively coupled to an aerial circuit A. One of the spark-balls $\mathrm{S}$ should be earthed, and a point at the opposite end of the inductance $\mathrm{T}_{1}$ should be connected to an insulated metal plate $\mathrm{P}_{2}$, which may be conveniently a zinc plate, 30 cms. or 12 inches square. A long helix $\mathrm{H}$ is prepared which may be 2 or $2 \frac{1}{2}$ metres in length, consisting of fine insulated wire wound in one layer on cbonite rods or tubes about 4 or 5 cms. in diameter. This helix is supported in a horizontal position and well insulated, and one end of the helix is connected to an insulated metal plate $P_{1}$ of the same size 


\section{Propagation of Electric Wares along Spiral Wires.}

as the one $\mathrm{P}_{2}$ on the oscillating circuit, and these plates are placed parallel to each other at a distance of a few centimetres more or less. The helix is provided with a curved metal saddle Sl which slides on it, being made to fit closely by a few layers of interposed tinfoil, and this saddle is connected by a flexible wire with the earth. Three vacuum-tubes $V$ should be provided, which may be conveniently attached to a sort of lazy-tongs arrangement whereby they.can be spaced out at equal distances. The process of measuring the frequency of the oscillating circuit consists in sliding the earthed saddle along the helix until a position is found in which there is a node of potential $\mathrm{N}$ halfway between the saddle and the end plate, and an antinode An at the middle of each half of the section of the helix on either side of the node. When this position is found, the length of the helix interposed between the end plate $P_{1}$ and the saddle $S I$ is equal to one wave-length on the helix. If the velocity of electric waves along this helix has previously been determined as described in this paper, the quotient of this measured velocity by the observed length of the wave on the helix gives the frequency of the oscillation. Having obtained the frequency of the oscillating circuit, we divide this frequency reckoned in fractions of a second into 1000 millions, a number representing very nearly the velocity of Hertzian waves in free space in feet per second, and the quotient is the length of the aerial aether wave in feet.

The velocity of tree ather waves in space is sufficiently near to $10^{9}$ feet per second to make the above rule quite accurate enough for practical purposes.

On comparing this wave-length with the length of the aerial we can decide at once whether the wave being sent ont is the fundamental or a higher harmonic of the radiating antenni.

In another place the writer his suggested the term limascope (from $\kappa v \mu \alpha, a$ wave) as the nawe for appliances of all kinds used for detecting electric waves. He would now suggest the term hummeter (analogous to ammeter) as the name for the above described instrument for measuring the length of electric waves. An instrument of this kind is of great practical use in connexion with Hertzian wave-telegraphy, as it enables us to compare the wave-length of the radiation used with its telegraphic effectiveness. Thus a wave 300 feet in length travels well over sea-surface, but it will not go well across towns and land, whereas a wave of five times that length travels well across land districts thickly covered with houses or trees or irregular elevations. $\Lambda$ s an example of such a measurement the following figures may be given. Employing the above described ebonite-core helix on 
which the wave-velocity was $172 \times 10^{6} \mathrm{cms}$./sec. with a certain wireless transmitter, the wave-length on the helix was found to be $65 \mathrm{cms}$. Hence the frequency of the oscillations used was $172 \times 10^{6} / 65=2 \cdot 65 \times 10^{6}$, and the corresponding length of the "wireless wave" is 377 feet. Since the capacity used in the spark-circuit was $0.006 \mathrm{mfd}$., this measurement also tells us that the effective inductance of the oscillation transformer employed with it was 600 centimetres. By noting the increase in the wave-longth on the helix produced by adding a small inductance or capacity to the oscillating circuit, it is obvious that the values of this addition can be calculated. In this manner the inductance of a foot or two of copper wire coiled into one or two turns can easily be measured.

XLIII. Chemical Dịssociation and Electrical Conductivity. By A. E. Garrett and R. S. Willows, B.A., D.Sc.*

TN the Philosophical Magazine for July 1899 there 1 appeared a paper by Beattie entitled "Leakage of Electricity from Plates." When various mixtures of substances were placed on the insulated plate of an air-condenser and heated, it was found that a leakage of electricity took place, this being, in several cases, apparently independent of the sign of the charge. The temperatures used were between $300^{\circ}$ and $400^{\circ}$. Similar effects were obtained if the substances were placed on the earthed plate.

Shortly after the appearance of this paper one of us repeated the experiments and verified the results generally. The apparatus used was similar to Beattie's. It was found, however, in a good many cases, that the rate of leak depended in a great measure on the sign of the charge given to the insulated plate. In a later paper + Beattie found the same result. He showed that if positive electricity leaked from the plate when the substance was on it, then it was incapable of holding a negative charge when that substance was transferred to the earthed plate of the condenser.

The objects of the experiments described in the following paper were to discover the origin of the leak, or, in terms of the ionization theory, to find out the seat of the ionization, and also obtain information concerning the nature of the ions in some of the cases. As a good many of the new observations and facts have been anticipated in Beattie's second paper, only those are given which bear directly on these objects.

* Communicated by the Physical Society : read June $24,1904$.

$\dagger$ Phil. Mag. A pril 1901. 
Fra. 1.
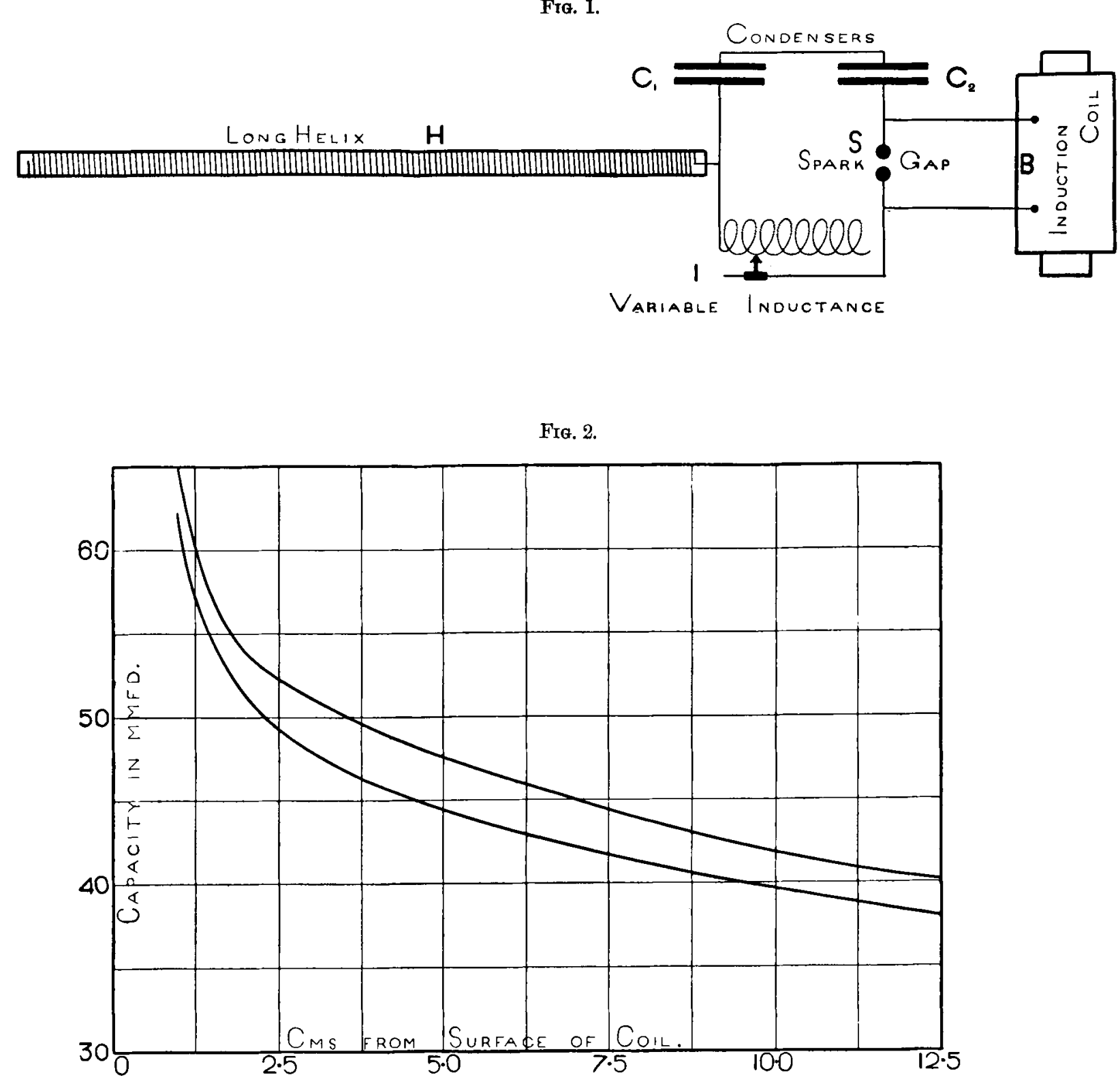

FIG. 4

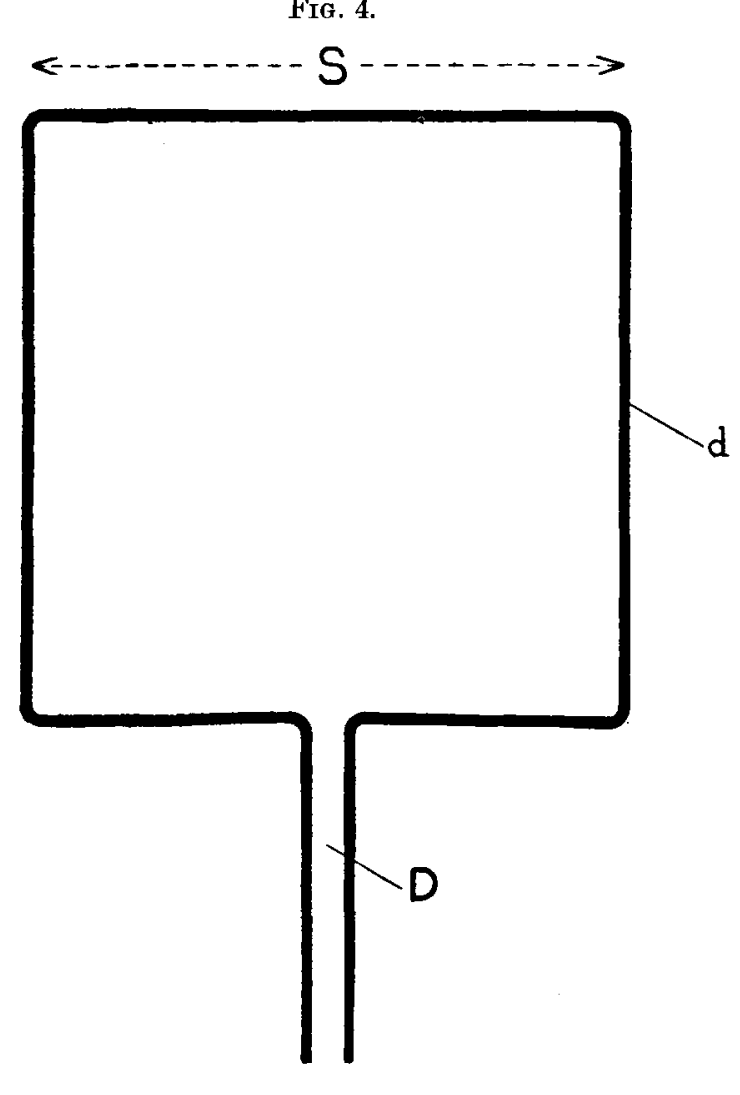

Square Inductance
Fra. 3.
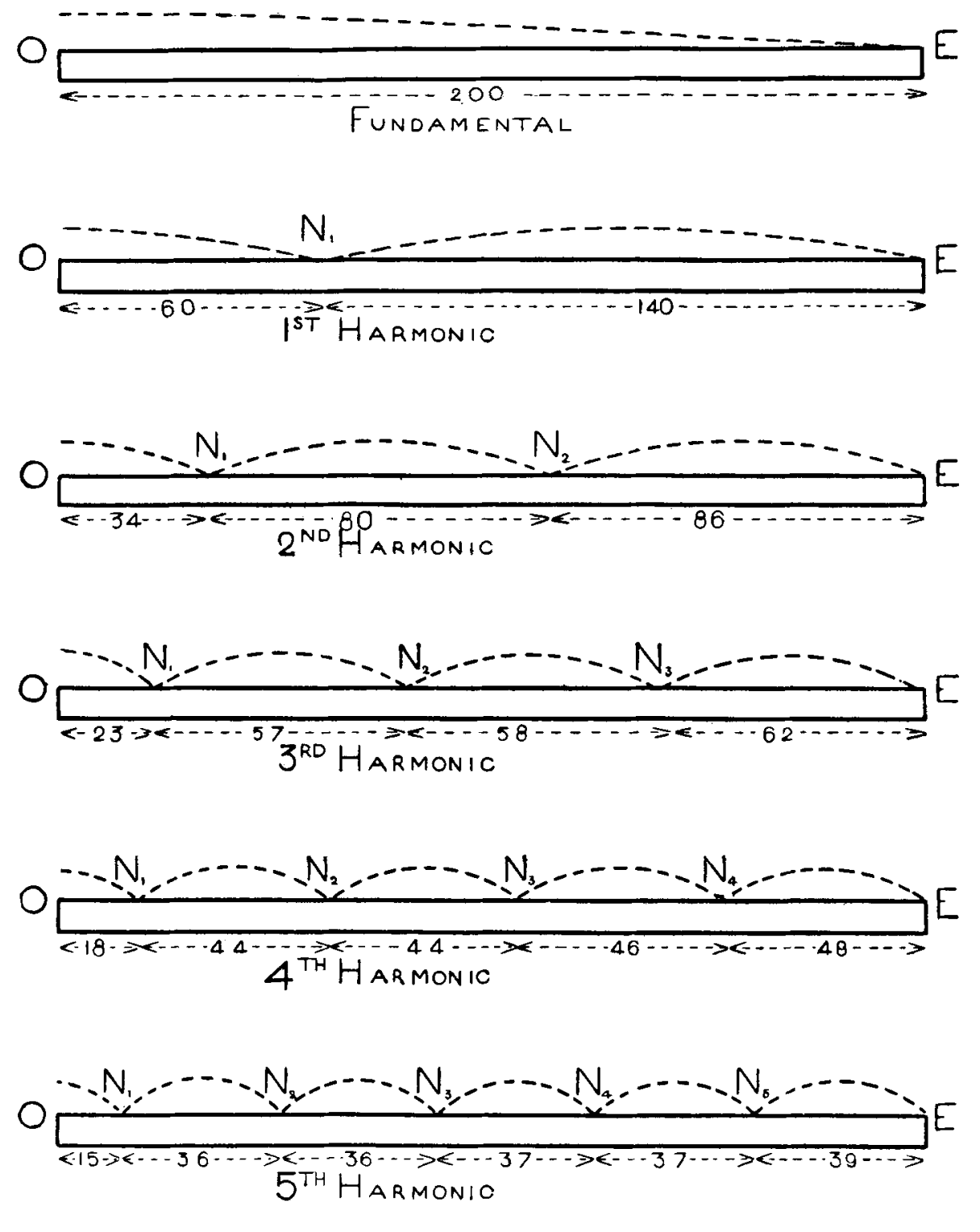

LENGTHS IN CMS

FIG. 5

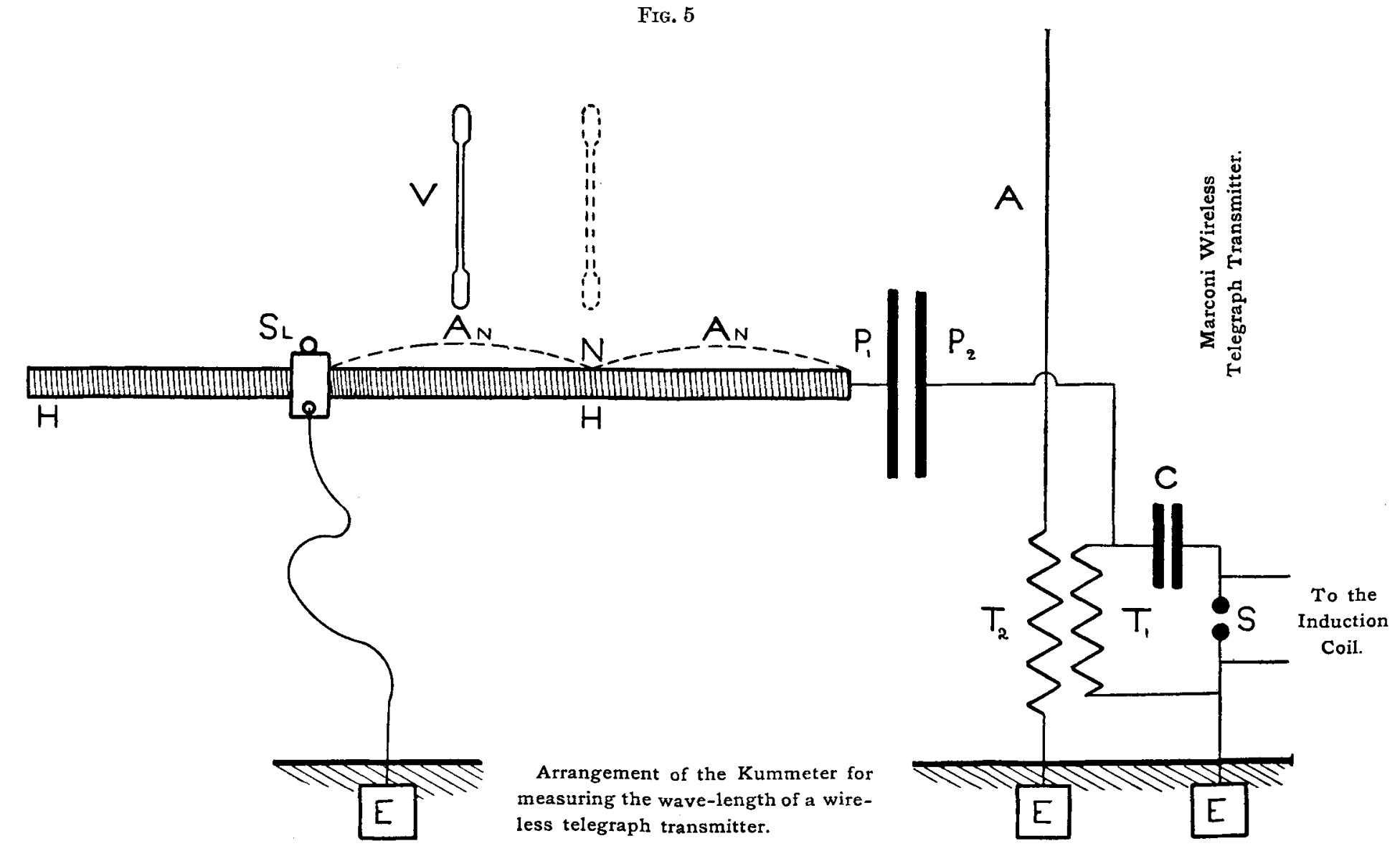

